
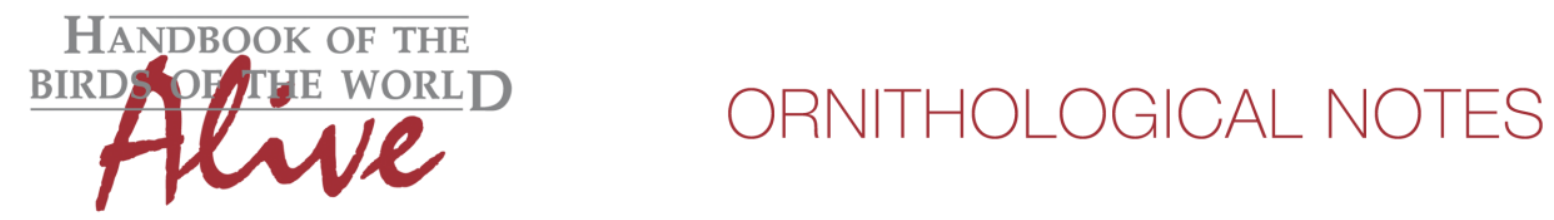

\title{
Notes on the vocalizations of Variegated Antpitta (Grallaria varia)
}

Peter Boesman

In the following we briefly analyze and compare voice of the different races of Variegated Antpitta (Grallaria varia). We also try to quantify the extent of any vocal differences using the criteria proposed by Tobias et al. (2010), as a support for taxonomic review. We have made use of sound recordings available on-line from Xeno Canto (XC).

Song of all races is very similar. There are two groups with clearly disjunct ranges, for which we have measured some basic sound parameters:

\begin{tabular}{ll} 
Group 1: Guianan/Amazonian g \\
\hline length & $2.6-4.4 \mathrm{~s}$ \\
start freq. & $420-470 \mathrm{~Hz}$ \\
max. freq. & $470-530 \mathrm{~Hz}$ \\
end freq. & $470-510 \mathrm{~Hz}$ \\
max note length & $0.26-0.5 \mathrm{~s}$ \\
\# notes & $10-14$ \\
fade-out? & yes or no
\end{tabular}

Group 2: SE Brazilian group ( $n=8)$

length

start freq.

max. freq.

end freq.

max note length

\# notes

fade-out? 3.3-3.7s

$415-490 \mathrm{~Hz}$

$520-570 \mathrm{~Hz}$

$460-550 \mathrm{~Hz}$

0.22-0.45s

13-17

mostly yes, some no

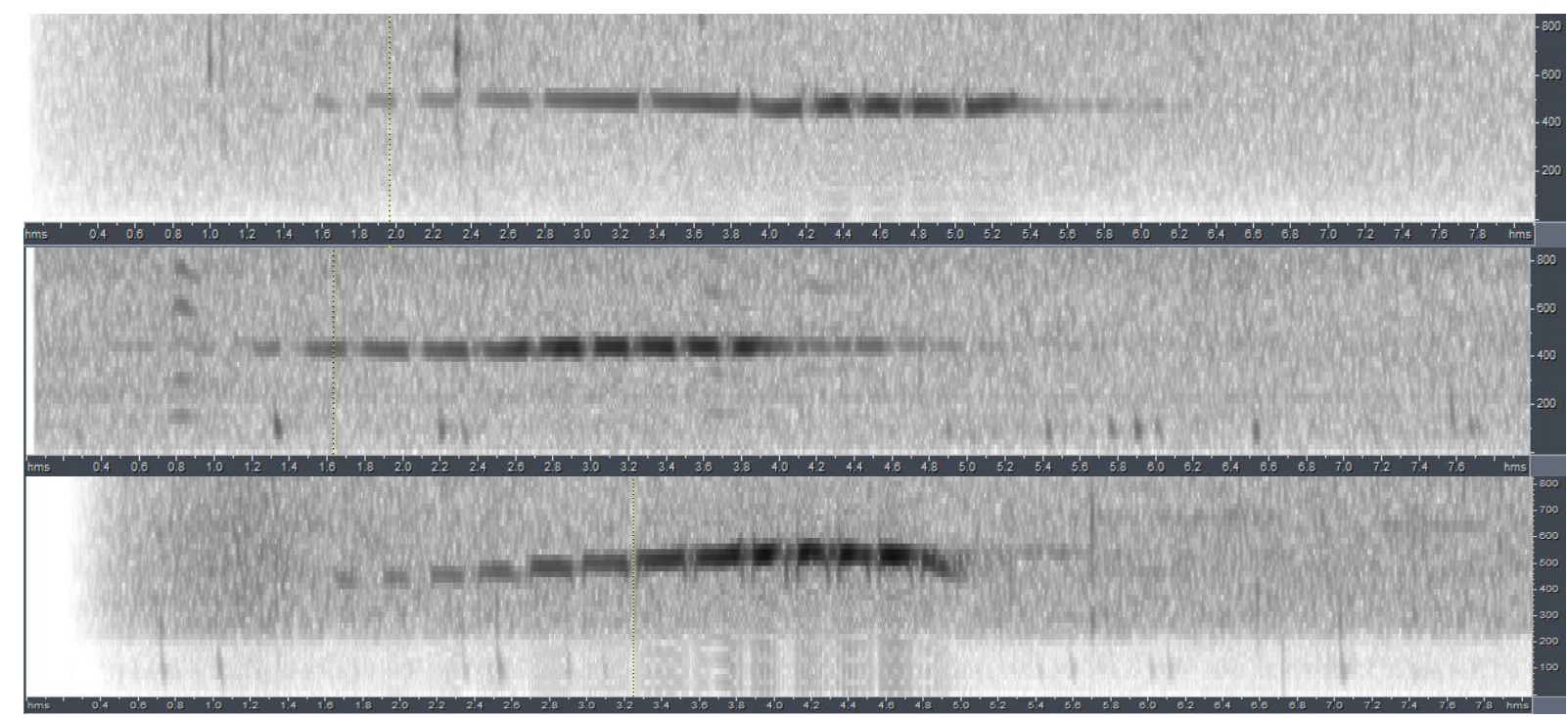

Figure 1: from top to bottom: typical song of group 1: (French Guyana and Carajas,Brazil) and group 2 (SE Brazil) 
The main difference seems to be the number of notes, which overlaps only slightly (score 12). SE Brazilian birds also tend to reach higher frequencies (score 1).

Total score 2-3.

All in all, vocal difference between these 2 groups seems to be minor.

This note was finalized on 15th June 2015 , using sound recordings available on-line at that moment. We would like to thank in particular all the sound recordists who placed their recordings for this species on XC.

\section{References}

Tobias, J.A., Seddon, N., Spottiswoode, C.N., Pilgrim, J.D., Fishpool, L.D.C. \& Collar, N.J. (2010). Quantitative criteria for species delimitation. Ibis 152(4): 724-746.

\section{Recommended citation}

Boesman, P. (2016). Notes on the vocalizations of Variegated Antpitta (Grallaria varia). HBW Alive Ornithological Note 70. In: Handbook of the Birds of the World Alive. Lynx Edicions, Barcelona. (retrieved from http://www.hbw.com/node/931957 on 17 May 2016). 